¿QUIÉN ES B. TRAVEN?

Jaime Perales Contreras*

RESUMEN: Durante toda su vida, la identidad de Bruno Traven fue tema de debate. A cuarenta años de su muerte, como breve homenaje, un recorrido de la vida y obra de este fascinante narrador, autor de la famosa novela El tesoro de la Sierra Madre.

PAlABRAS ClaVE: Bruno Traven, El tesoro de la Sierra Madre, Humphrey Bogart, John Huston, cine en México.
ABSTRACT: Throughout his life, Bruno Traven's identity has been a source of debate. On the fortieth anniversary of his death, we pay him homage by revisiting the life and works of this fascinating narrator, author of the famous novel, The Treasure of the Sierra Madre.

KeYwords: Bruno Traven, The Treasure of the Sierra Madre, Humphrey Bogart, John Huston, cinema in Mexico. 


\section{¿QUIÉN ES B. TRAVEN?}

Ret Marut, Traven Torsvan, Hal Croves, son uno y trino, como la santísima trinidad. Los tres son los nombres mas usados por ese deicida literario que fue B. Traven. Durante muchos años, la identidad del millonario escritor, ¿alemán, polaco, norteamericano, mexicano? es celoso motivo de ambiciosas pesquisas periodísticas. Detectives y abogados, periodistas $\mathrm{y}$ académicos, disputan, furiosamente, la primicia de haber descubierto la verdadera identidad del excéntrico narrador de historias. Y es que, hasta la fecha, en su aniversario luctuoso, a cuarenta años de su presunta muerte (1969), todavía existen dudas sobre la identidad de B. Traven. Menos complejo que Malcolm Lowry y más divertido que Graham Greene y D.H.
Lawrence juntos, sus relatos son poderosamente adictivos: son vigorosas infusiones de adrenalina. El único testimonio de su existencia son sus libros que han vendido más de 25 millones de copias, traducidos a treinta idiomas. Su obra más conocida, $E l$ tesoro de la Sierra Madre, protagonizada por Humphrey Bogart, y llevada a la pantalla por John Huston, ganó tres oscares en 1948 (dirección, guión cinematográfico y actor de reparto). Además, fue considerado por Stanley Kubrick como uno de los 10 filmes que se hubiera llevado a una isla desierta (obviamente desierta, pero con electricidad y pantalla de cine). Asimismo, el director Paul Thomas Anderson, (Magnolia y Boggie Nights), confesó que estaba viendo la película, mientras 
escribía el borrador de su última última película: There Will Be Blood. Cuenta el periodista mexicano Luis Suárez, uno de los que presume haber sido el único que pudo conseguir una entrevista con el novelista, que Traven, bajo el nombre de Hal Croves, el agente literario del autor, se reunió con Humphrey Bogart en un balneario de San José Purúa, Michoacán, en donde ambos hicieron la edición de la película que se filmó completamente en México. Una vez concluido el trabajo, Croves desapareció del balneario y Bogart no lo volvió a ver en su vida.

Con esta duda sobre la identidad de Traven, el novelista mexicano Luis Spota, en el mismo año en que se filmó El tesoro de la Sierra Madre (1948), se propuso averiguar quién era B. Traven. Spota descubrió que el escritor vivía casi todo el tiempo en una pensión en el puerto de Acapulco. $\mathrm{Su}$ correo lo recibía en un apartado postal situado a unas cuadras de la pensión. Luis Spota viajó a Acapulco con cámara lista $\mathrm{y}$, como precursor de los tan odiados paparazzi, (término que todavía no se usaría sino hasta que Federico Fellini lo popularizó en La Dolce Vita, 1960), le disparó certeramente una foto a Traven cuando éste recogía el correo. Spota encontró que la persona de la imagen era ni más ni menos que Harold Croves, el agente literario del autor. El misterio aparen- temente estaba resuelto y el resultado de la investigación de Spota se publicó en la revista mexicana Mañana. Sin embargo, al poco tiempo de celebrada la revelación de la década, se publicó en Life una carta firmada por Croves que negó de manera rotunda y categórica ser B. Traven. Dice el mismo Luis Suárez que su identidad fue tan celosamente perseguida que su traductora oficial al español, la guapa Esperanza López Mateos (hermana del presidente mexicano) fue asediada por periodistas, argumentando que ella era B. Traven. Cuando ella se suicidó, se dijo que B. Traven había muerto. Tanto escándalo causó que su hermano, el presidente López Mateos, aseguró ante la prensa que ni él ni su finada hermana eran B. Traven.

¿Por qué tanto misterio por guardar su identidad? Se dice que Traven era alemán y que escapó del país usando el nombre de Ret Marut, actor de teatro, novelista, crítico del feroz nacionalismo germano y de la guerra, fue, además, uno de los muchos que participaron en la breve revolución bávara en Alemania (1918-1919). Después de una trifulca terrible, los soldados aprehendieron a la mayoría de los simpatizantes del gobierno socialista, incluyendo a Marut y, acusado de crímenes de alta traición, se auguraba su potencial sentencia de muerte. El escritor pudo escapar de sus captores 
NOTAS

y vivió un tiempo oculto. Marut pudo abandonar clandestinamente Alemania en barco, convirtiéndose en eterno fugitivo del Estado alemán. En su primera novela, El barco de los muertos, se encuentran similitudes con lo que le pasó a Ret Marut en Alemania. Se dice que Marut trabajó en México como obrero, en donde le apodaban "el Gringo", por sus ojos azules y pelo rubio. No se supo más de él y después, misteriosamente, apareció un hombre con sus características físicas que solicitó la nacionalidad mexicana, bajo el nombre de Traven Torsvan, norteamericano, nacido en Chicago.

A Gerd Heidemann, reportero del diario alemán Stern, le ordenaron en 1962 comenzar un reportaje que aclarara, de una vezy por todas, la identidad de Traven. Heidemann reunió 42 carpetas llenas con dos mil quinientos folios en el que trató de ligar la identidad de Ret Marut con B. Traven. Viajó a España, Holanda, Brasil y Estados Unidos para completar su investigación. Recorrió 58 iglesias en Chicago tratando de encontrar el registro civil de Traven Torsvan en sus diversas variantes. No lo encontró. Lo único que pudo hallar fue una fotografía de Marut en una obra de teatro representada en Berlín en 1914 y unas fotos tomadas a Traven Torsvan en Chiapas en 1954 y en Hamburgo en 1959. Las fotos al cotejarse eran asombrosamente parecidas. Sin embargo, la distancia física en el tiempo no podía dar una respuesta definitiva.

El barco de los muertos se publicó originalmente en Alemania y la novela tuvo gran éxito. Para algunos críticos es la mejor. Su traductora, Esperanza López Mateos, lo descubrió en una librería y, absorbida por el poderío del libro, lo devoró. En esa época trabajaba como agente editora. Y, después de buscar más libros de $\mathrm{B}$. Traven, decidió contactarlo. Escribió a la editorial neoyorkina Alfred A. Knopf para adquirir los derechos para hacer dos películas basadas en sus novelas El puente de la selva y La rebelión de los colgados. Solicitó el precio de los derechos y el posible contacto con el autor. Al poco tiempo, Traven Torsvan la contactó telefónicamente para conocerse en un pueblecito en Michoacán. Según cuenta Suárez, probablemente los dos viajaron en el mismo tren sin conocerse. Ambos, al verse, debieron sentir un especial impacto y tal electricidad que ella se encargó de todos sus asuntos literarios. Tradujo todos sus libros al español y también hizo la promesa de no revelarle a nadie la verdadera identidad de B. Traven. Hal Croves, como agente literario de Traven, apareció cuando B. Traven tuvo que relacionarse con el glamoroso mundo de Hollywood. Croves fue el que dio la cara y el que se presen- 
tó a los escenarios en que se filmaba El tesoro de la Sierra Madre. Sin embargo, siempre negó ser B. Traven.

Durante los últimos años de la vida de B. Traven, el periodista mexicano Luis Suárez, contactó a Croves y publicó en la revista mexicana Siempre!, de octubre de 1966, un reportaje titulado Siempre! revela, al fin, el misterio literario más apasionante del siglo, y presenta al mundo a B.Traven. Quién es, cómo es, cómo vive y cómo piensa el extraordinario novelista hecho leyenda. The New York Times del 20 de noviembre de ese año, comentó de ese artículo de Siempre!, que Traven había concedido la primera entrevista con la prensa (aunque no se le permitió a Suárez utilizar grabadora y tampoco se le dejó tomar fotografías), en más de cuarenta años de fama $\mathrm{y}$, a su vez, de vida monacal de reclusión $\mathrm{y}$ anonimato.

Luiz Suarez le hizo la primera pregunta que todo mundo quería formularle:

- ¿Por qué, señor Traven, hay tanto misterio en torno suyo?

- No hay ningún misterio sobre Traven. Docenas de periodistas alemanes han hecho su carrera del hombre del misterio, del misterio de Traven. Ellos han ideado el misterio y en esa idea se han mantenido para hacer su carrera periodística. Jamás contribuiré a aumentar ni a deshacer el misterio. Lo importante del escritor son sus libros, no su vida.

Traven, según narra Suárez, era, en ese entonces, un hombre de setenta y ocho años, de mediada estatura; sus ojos, cansados de escribir, eran auxiliados por un lente de aumento. Sobre el oído derecho tenía la conexión de un aparato para la sordera. En la entrevista, Suárez, de manera particular, menciona que Traven constantemente cambiaba de la tercera a la primera persona indistintamente. Como si B. Traven fuese un amigo o conocido. Cuando se le preguntó si sus libros denigraban a México, contestó: Hay que querer a México como es, con sus virtudes y sus defectos. Yo quiero a México. Por eso, como autor, siento como un mexicano y escribo las cosas tal y como son. Por eso tomo siempre el punto de vista mexicano. ¿Cuál otro voy a tomar si siento a México? Así es Traven.

B. Traven murió el miércoles 26 de marzo de 1969, en la ciudad de México, a los setenta y ocho años. Uno de los lectores de la nota necrológica escribió al día siguiente a The New York Times y formuló la siguiente duda: ¿Si hay tanto misterio en torno a la persona de B. Traven, cómo saben que murió? Pregunta válida. Larry Rother, también del Times, en 1990 le hizo una entrevista a su viuda, Rosa Elena Luján, y le preguntó si su esposo 
NOTAS

Traven Torsvan había sido el legendario B. Traven. Ella contestó afirmativamente, junto a la vieja máquina Remington que él utilizaba para resguardarse del mundo y proyectar sus ficciones: Él me dijo que revelaraque él era Ret Marut, el revolucionario que había vivido en Alemania, cuando él muriera y no antes. La razón fundamental, según explicaba, era que Traven tenía miedo de ser deportado si el gobierno alemán sabía su verdadera identidad. El germanista Karl Siegfred Guthke, autor del libro $B$. Traven: The Life Behind the Legends, concluyó que Ret Marut y B. Traven eran la misma persona. Sin embargo, afirmó que la vida de Marut puede rastrearse hasta 1907. Antes de esa fecha, es un enigma, ya que él vivió en San Francisco en ese tiempo y todos sus papeles fueron destruidos en el terremoto de 1906. En un documental televisivo de la British Broadcasting Corporation, llamado The Man Who Was B. Traven, se conclu- yó que el verdadero nombre de B. Traven fue Hermann Albert Otto Maximizan Beige, quien nació en 1882 en el condado de Swiebodzin, en lo que es ahora Polonia. Sin embargo, Luján y Guthke afirmaron que esa hipótesis no era del todo convincente. La señora Luján recordó que Traven solía decirle: Soy la persona más libre del mundo: puedo escoger los padres que yo quiero, el país que yo quiero, la edad que yo quiero, pero, en realidad, ella confesó que Traven nunca supo dónde o cuándo nació: nunca tuvo un acta de nacimiento. Algunos otros apellidos a los que Traven se asocia, son: Arnold, Barker, Feige, Kraus, Lainger, Wienecke y Ziegelbrenner. También se rumoró que $B$. Traven nunca existió, que fue, como diría Borges, una alucinación colectiva, un espejismo, $\mathrm{y}$ que, simplemente, fue una invención del escritor norteamericano Jack London. 